\title{
Alimento para fins especiais: ingredientes, elaboração e aglomeração
}

\author{
Food for special needs: ingredients, \\ development and agglomeration
}

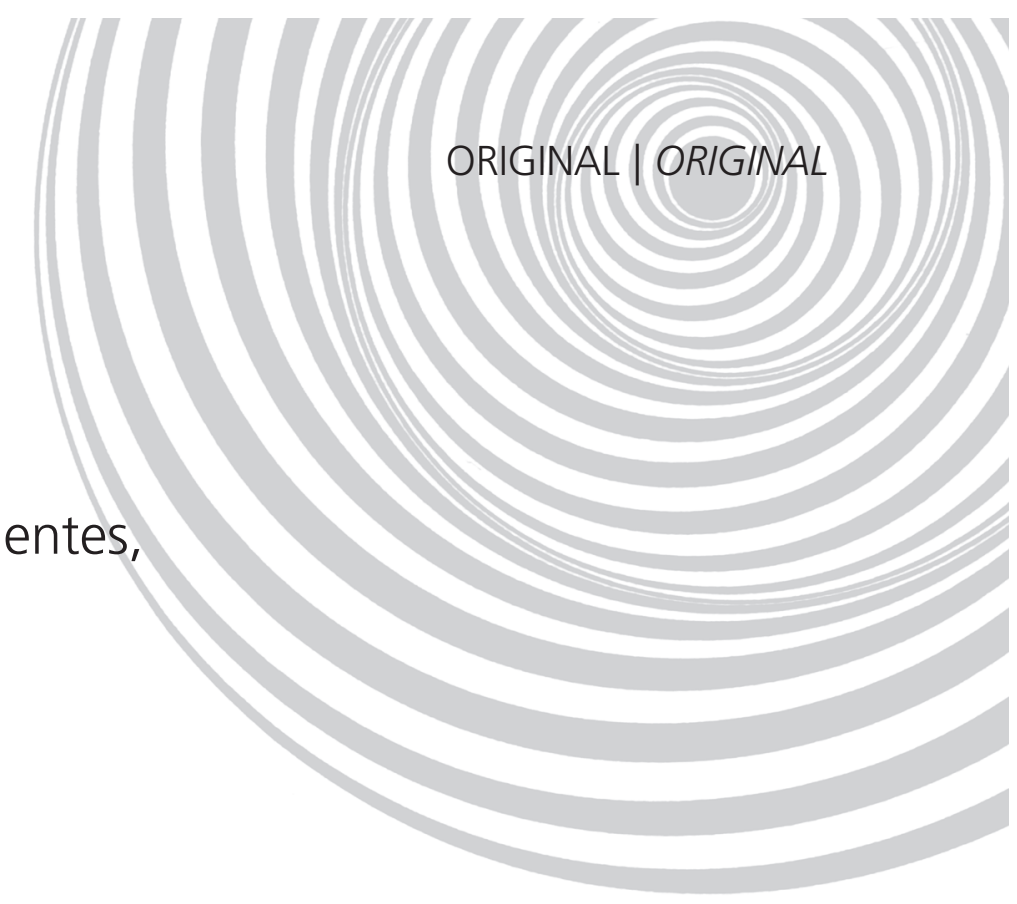

Luciana AZEVEDO'

Christiane MILEIB ${ }^{2}$

Fernanda Zaratini VISSOTTO3

Luciano Bruno de CARVALHO-SILVA'

RE S U M O

\section{Objetivo}

Desenvolver uma dieta enteral nutricionalmente completa, com condições ajustadas de aglomeração, visando contemplar as características físicas e químicas desejadas para esse alimento especial.

\section{Métodos}

Como ingredientes foram utilizados maltodextrina, óleo de canola, triglicerídios de cadeia média, goma acácia, inulina e frutooligossacarídeos, proteínas do soro de leite, isolado proteico de soja, vitaminas e minerais. Após os ajustes das quantidades e proporções dos ingredientes, a formulação foi aglomerada e submetida às análises de composição centesimal, molhabilidade, densidade aparente, atividade de água, viscosidade e cor.

\section{Resultados}

Obteve-se uma fórmula contendo $1 \mathrm{kcal} . \mathrm{mL}^{-1}$, normoproteica $\left(3,9 \mathrm{~g} .100 \mathrm{~mL}^{-1}\right)$ e normolipídica $\left(3,9 \mathrm{~g} .100 \mathrm{~mL}^{-1}\right)$. Após a aglomeração da dieta, observaram-se os seguintes resultados: molhabilidade de 0,262g.5. ${ }^{-1}$, densidade aparente de $0,317 \mathrm{~g} \cdot \mathrm{cm}^{-3}$ e atividade de água de 0,393. A análise de cor indicou redução da luminosidade e aumento dos parâmetros de cor $a^{*}$ e b*, apresentando leve variação para o vermelho e forte presença do amarelo.

\section{Conclusão}

Os ingredientes empregados, e suas respectivas proporções, bem como o processo de aglomeração, possibilitaram a obtenção de um alimento para fins especiais com propriedades bioativas. O processo de aglomeração possibilitou uma dieta de fácil reconstituição e utilização através de sondas, facilitando a infusão e, consequentemente, a diminuição de intercorrências.

Termos de indexação: Dieta enteral. Dietas. Nutrição enteral. Pós para preparo de alimentos.

\footnotetext{
1 Universidade Federal de Alfenas, Faculdade de Nutrição. R. Gabriel Monteiro da Silva, 714, Centro, 37130-000, Alfenas, MG, Brasil. Correspondência para/Correspondence to: L.B. CARVALHO-SILVA. E-mail: <luciano@unifal-mg.edu.br>.

${ }^{2}$ Universidade Federal de Viçosa, Programa de Pós-Graduação em Ciência e Tecnologia de Alimentos. Viçosa, MG, Brasil.

${ }^{3}$ Instituto de Tecnologia de Alimentos, Centro de Pesquisa e Desenvolvimento de Cereais e Chocolate. Campinas, SP, Brasil.
} 
316 | L. AZEVEDO et al.

\section{A B S T R A C T}

\section{Objective}

This study aimed to develop a nutritionally complete enteral diet, with adjusted agglomeration conditions, and determine the physical and chemical characteristics required by this special food.

\section{Methods}

The ingredients were maltodextrin, canola oil, medium-chain triglycerides, acacia gum, inulin, fructooligosaccharides, milk whey protein, soy protein isolate, vitamins and minerals. After the quantities and proportions of the ingredients were adjusted, the formula was agglomerated and analyzed for percent composition, moisture, apparent density, water activity, viscosity and color.

\section{Results}

The resulting diet contained $1 \mathrm{Kcal}_{\mathrm{mL}} \mathrm{m}^{-1}$ and normal protein $\left(3.9 \mathrm{~g} .100 \mathrm{~mL}^{-1}\right)$ and fat $\left(3.9 \mathrm{~g} .100 \mathrm{~mL}^{-1}\right)$ levels. After agglomeration, the following results were obtained: moisture $0.262 \mathrm{~g} \cdot \mathrm{s}^{-1}$, apparent density $0,317 \mathrm{~g} \cdot \mathrm{cm}^{-3}$ and water activity 0.393. Color analysis indicated a decrease in luminosity and increase in $a^{*}$ and $b^{*}$ colors, presenting a slight variation towards red and a strong presence of yellow.

\section{Conclusion}

The used ingredients and respective proportions, as well as the agglomeration process, resulted in a food for special needs with bioactive properties. The agglomeration process produced a diet that can easily be reconstituted and fed through catheters, facilitating infusion and consequently, reducing intercurrences.

Indexing terms: Enteral diet. Diets. Enteral nutrition. Powder for food preparation.

\section{N T R O D U Ç Ã O}

A nutrição enteral consiste de alimentos formulados para fins especiais que possam ser utilizados através de tubo de alimentação ou sonda, que pode instilar os nutrientes diretamente no estômago ou no intestino, dependendo da condição do indivíduo. Devido aos melhoramentos sensoriais dos produtos atualmente elaborados, muitas dessas dietas têm sido passíveis de serem utilizadas por via oral, o que incrementou sua distribuição no mercado consumidor. Tais formulações são sistemas complexos por terem em sua constituição todos os nutrientes requeridos. Essa complexidade é facilmente notada na possibilidade de interações entre minerais, as quais podem interferir na absorção de nutrientes e na qualidade nutricional dessas dietas ${ }^{1,2}$.

Essa alimentação pode constituir a via preferencial/única de nutrição para diversas situações clínicas, como pacientes neurológicos, psiquiátricos, politraumatizados e em estados críticos, visando a auxiliar nas funções metabólicas dos indivíduos submetidos ao aporte nutricional por administração enteral ${ }^{3,4}$. Essa via é indicada para indivíduos cujo trato gastrointestinal é funcionante, mas cuja ingestão oral é inadequada para prover de dois terços a três quartos das necessidades diárias nutricionais ${ }^{1}$. Nesse contexto, as dietas enterais perfazem uma importante forma de alimentação, impeditiva da desnutrição hospitalar, além da neutralização do estado catabólico induzido por diversas doenças ${ }^{5,6}$.

Apesar das prerrogativas da utilização da nutrição enteral, seu uso ainda é limitado devido aos custos quase sempre elevados das dietas industrializadas. Levantamento realizado pelo grupo de pesquisa, durante o período de 2006 a 2008, entre empresas que comercializam dietas enterais, considerando cinco marcas representativas entre os consumidores, indicou que os preços dessas dietas variaram entre $\$ 10,00$ e $\$ 50 / \mathrm{kg}$. Isso se justifica principalmente à demanda de tecnologia de produção e desenvolvimento de produtos, uma vez que os ingredientes utilizados na elaboração desses produtos estão disponíveis no mercado a baixo custo ${ }^{7}$.

Comercialmente, são encontradas formulações enterais em pó e líquidas. As vantagens de se utilizar os produtos em pó estão associadas a 
sua versatilidade no manuseio e no armazenamento ${ }^{8}$. Para essa finalidade, o desenvolvimento de dietas que agreguem valor, por apresentarem ingredientes especiais como prebióticos, é cotidianamente dificultado pela obrigatoriedade de se atingir um perfil de características físicas e químicas finais. Tal perfil deve permitir que esses produtos veiculem todas as recomendações nutricionais em 2000kcal; baixa viscosidade; total e rápida reconstituição, evitando processos de obstrução de sonda nos pacientes e otimização do processo de homogeneização das dietas ${ }^{9}$.

Quanto à reconstituição, acrescenta-se que, quando um pó é "despejado" sobre a superfície de um líquido, ocorrem quatro etapas. A primeira, molhabilidade, consiste na penetração do líquido para o interior da estrutura do pó devido à capilaridade. A segunda, imersibilidade, corresponde à imersão das partículas ou de porções de pó no líquido. A terceira etapa, dispersibilidade, representa a dispersão do pó no líquido. Finalmente, na quarta etapa, a solubilidade representa a dissolução das partículas pelo líquido, quando são solúveis ${ }^{10}$.

A fim de melhorar a reconstituição, normalmente, é empregada pelas indústrias processadoras de pós a simples mistura na elaboração dessas dietas. No entanto, esse processo não é garantia de que o produto apresente uma qualidade final desejável. Para essa finalidade, pode-se utilizar a aglomeração, também conhecida como instantaneização, que permite transformar um produto ou uma mistura de produtos em pó em grânulos, modificando sua estrutura física, contribuindo para a reconstituição em meio líquido"1.

Nesse contexto, foi desenvolvida uma dieta enteral nutricionalmente completa, com condições ajustadas de aglomeração, visando contemplar as características físicas e químicas desejadas para esse alimento especial.

\section{MÉ T O D OS}

Para a formulação da dieta enteral, teve-se como propósito alcançar a distribuição ener- gética de 55\% de carboidratos, compostos exclusivamente por maltodextrina, fornecida pela Cargill Agrícola S.A.; de $16 \%$ de proteínas, resultante da mistura de concentrado proteico de soro de leite (Lacprodan 80) e isolado proteico de soja (Supro ${ }^{\circledR} 783$ ), doados pela Arla Foods Ingredients e The Solae Company, respectivamente; e de $29 \%$ de lipídeos, provenientes de óleo de canola e Triglicerídios de Cadeia Média (TCM). Como fontes de fibras e prebióticos, foram utilizados goma acácia (Fibregum B), cedida pela Colloides Naturels International (CNI); inulina (Raftilineâ GR) e frutooligossacarídeos (RAFTILOSE ${ }^{\circledR}$ P95), os dois últimos doados pela empresa ORAFTI - Active Food Ingredients.

Foi adicionada à formulação, mistura de vitaminas e minerais nas quantidades recomendadas pela Agência Nacional de Vigilância Sanitária (ANVISA - RDC n 449, 1999) ${ }^{9}$, elaborada e fornecida pela M. CASSAB Comércio e Indústria Ltda; fibras doadas pela empresa ORAFTI - Active Food Ingredients; lecitina de soja cedida pela Solae Company; Butil hidroxi tolueno também cedido pela M. CASSAB Comércio e Indústria Ltda e aromatizantes, pela Pró-Aroma Indústria e Comércio.

Os ingredientes em pó foram adicionados por ordem decrescente de peso, considerando a quantidade fornecida de cada ingrediente e misturados manualmente à temperatura ambiente. Em seguida, foi acrescida uma solução pré-aquecida a $60^{\circ} \mathrm{C}$, contendo óleo de canola, lecitina de soja e TCM, por aproximadamente cinco minutos, até homogeneização.

A composição centesimal foi conduzida de acordo com a $A O A C^{12}$. As análises foram realizadas a partir da extração de proteína bruta, quantificada pelo método de análise de Kjeldahl; e de lipídeos totais, que foram determinados pelo método de Soxhlet. A umidade foi determinada em estufa a $105^{\circ} \mathrm{C}$ até a obtenção de peso constante, e as cinzas em mufla a $550^{\circ} \mathrm{C}$. Carboidratos totais foram estimados por diferença, subtraindo-se de $100 \%$ a soma dos valores obtidos para as determinações anteriores. Para a análise de fibras, foram utilizados os dados contidos nos laudos 
técnicos fornecidos pelas empresas Colloides Naturels International (CNI) e ORAFTI - Active Food Ingredients.

A aglomeração da formulação foi realizada no equipamento instantaneizador piloto, da ICF Industrie Cibec S.P.A. (Maranello-MO, Itália), e a alimentação do equipamento, através de uma tremonha, no interior da qual havia uma escova rotativa que forçava a passagem do pó contra uma grelha de abertura quadrada de $1 \mathrm{~mm}$. Para caracterização física da dieta enteral, utilizou-se como padrões duas formulações em pó, as quais foram denominadas dieta comercial A e B, considerando os valores obtidos no mercado consumidor, de $\$ 31,50$ e $\$ 20,00 \mathrm{Kg}^{-1}$, respectivamente.

Para o ajuste do processo de aglomeração, obtiveram-se como condições a grelha de mesh quadrada $1,0 \mu \mathrm{m}$, secador rotativo $60^{\circ} \mathrm{C}$, temperatura de secagem de $60^{\circ} \mathrm{C}$, vazão de sólidos da alimentação de $400 \mathrm{~g} \cdot \mathrm{min}^{-1}$, rotação do secador de 52rpm e pressão de vapor de 1,8 bar.

Para a avaliação da dieta produzida por aglomeração, foram realizadas análises de molhabilidade, densidade aparente, atividade de água, viscosidade e cor. A molhabilidade foi medida adaptando-se a metodologia proposta por Hla \& Hogekamp ${ }^{13}$, que consiste na queda de $2 \mathrm{~g}$ de amostra sobre $400 \mathrm{~mL}$ de água destilada a $25^{\circ} \mathrm{C}$, com posterior cronometragem do tempo necessário para que todas as partículas se molhassem. As determinações foram realizadas dez vezes para cada amostra. O cálculo da taxa da molhabilidade foi feita através da equação $T=\mathrm{N} / \mathrm{t}$, sendo: $T$ a taxa de molhabilidade $\left(\mathrm{g} . \mathrm{s}^{-1}\right)$; $\mathrm{N}$, a massa da amostra (g) e t, o tempo (s).

A densidade aparente foi determinada em triplicata com base em sua definição: massa de partículas que ocupa determinado volume. A análise constitui-se da padronização da distribuição do produto, baseado no volume ocupado por ele ${ }^{14}$. A amostra foi colocada em proveta graduada até alcançar o equivalente a $150 \mathrm{~mL}$, com a subseqente pesagem.

Para a atividade de água, foi utilizado o analisador de atividade de água de bancada, mar- ca Decagon, modelo CX2, acoplado a um banho termostático para a estabilização da temperatura. As medidas foram realizadas em triplicata a $25^{\circ} \mathrm{C}$.

A viscosidade aparente foi determinada em reômetro Brookfield DV - III, na taxa de cisalhamento de 30rpm, similar à obtida nos processos de mastigação e deglutição do alimento, no tempo de leitura de 30s e spindles 16, 18, 31 expressa em centipoise $(\mathrm{CP})^{15}$. A viscosidade foi determinada em triplicata à temperatura de $25^{\circ} \mathrm{C}$.

Na determinação da cor utilizou-se o aparelho Konica Minolta, modelo CR 410, com capacidade de leitura em diferentes sistemas de cores, sendo utilizado o sistema $L^{*} a^{*} b^{*}$ (Commission Internationale de l'Éclairage - CIE, 1931).

Os dados foram comparados por ANOVA e teste de Tukey-Kramer, cujos valores de $p$ menores que 0,05 foram considerados significativos. O software ${ }^{16}$ utilizado foi o Statistical Package for the Social Sciences (SPSS) para Windows 15.1.

\section{RESULTADOSE DISCUSSÃO}

Com vistas a obter uma dieta com características de um alimento para fins especiais, com baixa viscosidade e fácil reconstituição, os ingredientes e suas quantidades foram ajustados. Nessa fase, buscou-se obter um produto normocalórico e normoproteico (Tabela 1) para atender a determinação da Anvisa ( $R D C n^{\circ}$ 449, de 9 de setembro de 1999$)^{9}$ para alimento nutricionalmente completo destinado à nutrição enteral.

Foram realizados ensaios prévios para adequação dos ingredientes adicionados à formulação. Para essa finalidade, foram avaliadas diferentes fontes proteicas, lipídicas, de minerais, vitamínicas e de fibras, sendo utilizadas como critério a adequação nutricional, as propriedades funcionais fisiológicas, a reconstituição em água, a viscosidade e a estabilidade. Para proteínas, as fontes empregadas foram Concentrado Proteico do Soro de Leite (CPS) e Isolado Proteico de Soja (IPS), com proporção de 70:30, respectivamente. 
As bases lipídicas - óleo de canola e Triglicerídeos de Cadeia Média (TCM) - foram empregadas na proporção de 80:20, respectivamente. O conteúdo mineral e vitamínico está apresentado na Tabela 2.

Como fonte de fibras, foram utilizadas a inulina, goma acácia e fruto-oligossacarídeos (FOS) nas proporções 40:30:24 respectivamente, as quais possuem alegação de ingredientes funcionais prebióticos ${ }^{11}$. O impacto da utilização da fibra na nutrição enteral baseia-se na sua relação com a diminuição dos episódios diarreicos, em comparação com o uso de fórmulas-padrão, além da redução no tempo de permanência hospitalar ${ }^{17,18}$. Os resultados da caracterização dos produtos submetidos às análises de molhabilidade, densidade aparente, atividade de água e viscosidade são apresentados na Tabela 3.
De acordo com os resultados obtidos para taxa de molhabilidade, a fórmula aglomerada apresentou valores significativamente inferiores $(p<0,05)$ à não aglomerada e às dietas comerciais A e $B$. A rápida molhabilidade observada foi favorecida pela expansão do espaço intersticial apresentado pelas partículas após a aglomeração, formando poros grandes que facilitaram a penetração de água e a diminuição do tempo para que as partículas ficassem molhadas ${ }^{19,20}$.

Outra propriedade que também depende do tamanho da partícula é a densidade. De acordo com o exposto na Tabela 2, nota-se que todas as dietas encontram-se dentro da faixa de 0,3 a $0,8 \mathrm{~g} \cdot \mathrm{cm}^{-3}$, normalmente apresentada pelos alimentos em pó. O processo de aglomeração influenciou positiva e significativamente a redução

Tabela 1. Determinação dos macronutrientes energéticos da dieta enteral*

\begin{tabular}{|c|c|c|c|c|c|c|c|c|c|c|}
\hline \multirow{2}{*}{ Componentes } & \multicolumn{2}{|c|}{ g. $100 g^{-1}$} & \multicolumn{2}{|c|}{ g. $100 \mathrm{~mL}^{-1}$} & \multicolumn{2}{|c|}{ g. $2000 \mathrm{kcal}^{-1}$} & \multicolumn{2}{|c|}{ Kcal.dia $^{-1}$} & \multicolumn{2}{|c|}{ \% Kcal.2000-1 } \\
\hline & $\mathrm{M}$ & DP & M & DP & $\mathrm{M}$ & $\mathrm{DP}$ & $M$ & $\mathrm{DP}$ & $\mathrm{M}$ & DP \\
\hline Proteína bruta & 16,1 & 16,1 & 3,9 & 0,20 & 79,7 & 0,46 & 318,8 & 0,23 & 15,7 & 0,45 \\
\hline Lipídeos totais & 13,7 & 13,7 & 3,7 & 0,17 & 67,5 & 0,35 & 607,5 & 0,21 & 30,0 & 0,37 \\
\hline Carboidratos $^{\star *}$ & 59,6 & 0,9 & 13,7 & 0,58 & 274,9 & 0,79 & 1099,6 & 0,81 & 54,3 & 0,69 \\
\hline
\end{tabular}

*Média (M) de três determinações mais desvio-padrão (DP). Valores obtidos conforme metodologia apresentada, sendo cinzas = 5,2g.100. 1, umida-de $=5,4 \mathrm{~g} \cdot 100^{-1}$; Fibras totais obtida por estimativa $=5,1 ;{ }^{* *}$ Calculado pela diferença $=100$ - (proteína + lipídeos + cinzas + umidade) Considerações: $2000 \mathrm{kcal}=$ necessidade diária; densidade energética $1 \mathrm{kcal} \cdot \mathrm{mL}^{-1}$, reconstituição de $493 \mathrm{~g} .2000 \mathrm{~mL}^{-1}$.

Tabela 2. Composição mineral e vitamínica utilizada em 2000kcal de dieta enteral.

\begin{tabular}{|c|c|c|c|}
\hline \multicolumn{2}{|c|}{ Vitaminas $^{*}$} & \multicolumn{2}{|l|}{ Minerais $^{*}$} \\
\hline Fonte & Quantidade & Fonte & Quantidade \\
\hline Vitamina A (palmitato de retinol) & $600,0 \mathrm{mcg} \mathrm{RE}^{* *}$ & Ferro (ferro quelato) & $9,5 \mathrm{mg}$ \\
\hline Vitamina D (colecalciferol) & $5,0 \mathrm{mcg}$ & Zinco (sulfato de zinco minohidratado) & $7,0 \mathrm{mg}$ \\
\hline Vitamina C (ácido ascórbico) & $45,0 \mathrm{mg}$ & lodo (iodeto de potássio) & $130,0 \mathrm{mcg}$ \\
\hline Vitamina E (acetato de tocoferol) & 10,0mg d-alfa-tocoferol & Flúor (fluoreto de sódio) & $4,0 \mathrm{mg}$ \\
\hline Vitamina $B_{1}$ (tiamina mononitrato) & $1,2 \mathrm{mg}$ & Cobre (sulfato de cobre) & $0,1 \mathrm{mg}$ \\
\hline Vitamina $B_{2}$ (riboflavina) & $1,3 \mathrm{mg}$ & Selênio (selenito de sódio) & $34,0 \mathrm{mcg}$ \\
\hline Vitamina PP (nicotinamida) & $16,0 \mathrm{mg}$ & Molibdênio & $45,0 \mathrm{mcg}$ \\
\hline Vitamina $\mathrm{B}_{6}$ (piridoxina) & $1,3 \mathrm{mg}$ & Cromo (cromo quelato) & $35,0 \mathrm{mcg}$ \\
\hline Ácido fólico (ácido fólico) & $240,0 \mathrm{mcg}$ & Manganês (sulfato de manganês monohidratado) & $2,3 \mathrm{mg}$ \\
\hline Vitamina $B_{12}$ (cianocobalamina) & $2,4 \mathrm{mcg}$ & Sódio (cloreto de sódio) & $2160,0 \mathrm{mg}$ \\
\hline Vitamina $\mathrm{H}$ (biotina) & $22,0 \mathrm{mcg}$ & Magnésio (óxido de magnésio anidro) & $250,0 \mathrm{mg}$ \\
\hline Pantotenato de cálcio & $5,0 \mathrm{mg}$ & Potássio (sulfato de potássio anidro) & $1581,0 \mathrm{mg}$ \\
\hline Vitamina K (fitomenadiona) & $65,0 \mathrm{mcg}$ & Cálcio (fosfato de potássio anidro) & $995,0 \mathrm{mg}$ \\
\hline Colina (citrato de colina) & $550,0 \mathrm{mg}$ & Fósforo & $513,0 \mathrm{mg}$ \\
\hline
\end{tabular}

* Quantidade utilizada em 493,0g de dieta (2000kcal); **RE: equivalente de retinol. 
Tabela 3. Características físicas apresentadas pelas dietas em pó

\begin{tabular}{|c|c|c|c|c|c|c|c|c|}
\hline \multirow{2}{*}{ Análises } & \multicolumn{2}{|c|}{ Dieta não aglomerada* } & \multicolumn{2}{|c|}{ Dieta aglomerada* } & \multicolumn{2}{|c|}{ Comercial $A^{*}$} & \multicolumn{2}{|c|}{ Comercial B* } \\
\hline & M & DP & M & DP & M & DP & M & DP \\
\hline Molhabilidade $\left(\mathrm{g} \cdot \mathrm{s}^{-1}\right)$ & 1,647 & $0,250^{b}$ & 0,262 & $0,100^{d}$ & 0,915 & $0,550^{c}$ & 1,802 & $27,010^{a}$ \\
\hline Densidade aparente $\left(\mathrm{g} \cdot \mathrm{cm}^{3}\right)$ & 0,464 & $0,001^{a}$ & 0,317 & $0,000^{b}$ & 0,467 & $0,000^{\mathrm{a}}$ & 0,462 & $0,001^{a}$ \\
\hline Atividade de água & 0,449 & 0,005 & 0,393 & 0,010 & 0,372 & 0,004 & 0,435 & 0,023 \\
\hline Viscosidade (cP) & 10,100 & $0,004^{b}$ & 10,000 & $0,003^{b}$ & 17,300 & $0,010^{\mathrm{a}}$ & 10,000 & $0,030^{b}$ \\
\hline
\end{tabular}

*Média (M) de três determinações mais desvio-padrão (DP).

Letras iguais na mesma linha não diferem estatisticamente pelo teste ANOVA e Tukey considerando $p<0,05$.

da densidade aparente dos pós, demonstrando que o aumento do diâmetro das partículas e a porosidade dos grânulos tornaram-se maiores e mais leves. Isso resultou em um produto com meIhores características de reconstituição. Observa-se que quanto menor a densidade aparente, maior será a porosidade do grânulo e maior a área de superfície das partículas expostas e susceptíveis ao umedecimento ${ }^{21}$.

Em estudos realizados por Colugnati ${ }^{21} \mathrm{e}$ Silva22, formulações aglomeradas, compostas por Isolado Proteico de Soja (IPS), soro de leite, maltodextrina e açúcar, apresentaram valores similares de densidade aparente, variando de 0,28 a $0,36 \mathrm{~g} \cdot \mathrm{cm}^{-3}$. Os quais foram justificados pela presença de maltodextrina na formulação, que favorece o aumento dos grânulos formados no processo de aglomeração e consequente redução da densidade aparente.

Além da granulometria, dois outros fatores que afetam a densidade dos produtos desidratados são a umidade e a atividade de água $\left(A_{a}\right)^{23}$. A formulação aglomerada, assim como as outras dietas avaliadas, apresentaram valores de $A_{a}$ próximos de 0,3, o que é esperado para alimentos em pó ${ }^{11,24}$. A redução na atividade de água da fórmula aglomerada foi devido à etapa de secagem dos grânulos à temperatura de $70^{\circ} \mathrm{C}$. Considerando as dietas padrões, não foi observada diferença significativa na atividade de água entre a dieta aglomerada $\left(A_{a}=0,393\right)$ e a comercial $A$ $\left(A_{a}=0,372\right)$.

Em relação à viscosidade, todas as dietas analisadas (Tabela 2) podem ser caracterizadas como produtos de consistência rala, por encon-
Tabela 4. Avaliação da cor das formulações enterais antes e após o processo de aglomeração.

\begin{tabular}{|c|c|c|c|c|}
\hline \multirow{2}{*}{$\begin{array}{l}\text { Coordenadas de } \\
\text { cromaticidade }\end{array}$} & \multicolumn{2}{|c|}{$\begin{array}{c}\text { Dieta não } \\
\text { aglomerada1 }\end{array}$} & \multicolumn{2}{|c|}{$\begin{array}{c}\text { Dieta } \\
\text { aglomerada } 1\end{array}$} \\
\hline & $M$ & DP & $\mathrm{M}$ & DP \\
\hline$L^{*}$ & 86,78 & $0,12^{\mathrm{a}}$ & 86,09 & $0,07^{b}$ \\
\hline$a^{*}$ & 1,04 & $0,04^{b}$ & 1,23 & $0,03^{a}$ \\
\hline$b^{*}$ & 15,35 & $0,13^{b}$ & 16,42 & $0,07^{a}$ \\
\hline
\end{tabular}

${ }^{1}$ Média (M) de três determinações mais desvio-padrão (DP). Letras iguais na mesma linha não diferem estatisticamente pelo teste ANOVA e Tukey considerando $p<0,05$.

trar-se na da faixa de 0 a $50 \mathrm{CP}^{11}$. Comparativamente, Montejo et al. ${ }^{25}$, também analisaram oito fórmulas comerciais, e verificaram valores de viscosidade entre 9 e 36 cP. As baixas viscosidades viabilizam o uso das fórmulas em sondas enterais de pequeno calibre, diminuindo os riscos de obstrução e facilitando o gotejamento constante. Nesse sentido, concluiu-se que o processo de aglomeração não interferiu na viscosidade da dieta enteral formulada, no entanto foi menor que a dieta comercial $A$, o que pode estar relacionado a sua composição química.

Os resultados da análise colorimétrica estão apresentados na Tabela 4. Constata-se que o processo de aglomeração alterou tanto a luminosidade quanto a cromaticidade do pó.

Para a determinação de cor, os parâmetros $L^{*}, a^{*}$ e $b^{*}$ foram comparados entre os pós antes e após a aglomeração, visando à análise do processo. Os valores de $L^{*}$, que indicam intensificação da luminosidade, foram menores na amostra aglomerada, possivelmente devido à formação de grânulos mais porosos com maior reflexão da luz e 
menor luminosidade. Já os valores da variável de cor $a^{*}$ foram aumentados com a aglomeração, intensificando-se as tonalidades de vermelho no produto em pó. Quanto ao parâmetro b* da cor, verificaram-se tonalidades amarelas mais intensas que a não aglomerada. Possivelmente, a cor adquirida pela dieta aglomerada, com o aumento da intensidade de cores, está relacionada à caramelização e à reação de Maillard, que ocorre principalmente em materiais que apresentam teores relativamente altos de açúcares totais ${ }^{26}$.

\section{O N CLUSÃ O}

Os ingredientes utilizados e as proporções determinadas permitiram o desenvolvimento de uma dieta enteral nutricionalmente completa, com $1 \mathrm{kcal} . \mathrm{mL}^{-1}$, normoproteico $\left(3,9 \mathrm{~g} \cdot 100 \mathrm{~mL}^{-1}\right) \mathrm{e}$ normolipídica $\left(3,9 \mathrm{~g} \cdot 100 \mathrm{~mL}^{-1}\right)$, contendo ingredientes funcionais bioativos, como as proteínas do soro de leite e as fibras, goma acácia, inulina e frutooligossacarídeos. Tal composição, associada às condições ajustadas do processo de aglomeração, permitiu que a fórmula desenvolvida atendesse as características de um alimento para fins especiais, que não obstruísse a sonda de infusão da dieta no indivíduo usuário, além das facilidades de reconstituição da mesma, o que pode ser uma etapa limitante quando se trata de preparo em instituições com maior número de pacientes, como hospitais.

\section{A GRADECIMENTOS}

Ao Departamento de Nutrição da Universidade Federal de Alfenas ao Centro de Pesquisa e Desenvolvimento de Cereais e Chocolate (CEREAL CHOCOTEC) do Instituto de Tecnologia de Alimentos de Campinas e à Fundação de Apoio à Pesquisa do Estado de Minas Gerais pelo apoio financeiro.

\section{COLABORADORES}

L. AZEVEDO e L.B.C. SILVA participaram da elaboração do projeto, do delineamento experimental, dos ajustes, aglomeração e caracterização das dietas, do tratamento estatístico e da confecção do manuscrito. F.Z. VISSOTTO participou do processamento de aglomeração das dietas. C. MILEIB participou dos ajustes, aglomeração e caracterização das dietas, do tratamento estatístico e da confecção do manuscrito.

\section{REFERÊ NCIAS}

1. Harvey L. Mineral bioavability. J Nutri. 2001; 31(4): 179-82.

2. Winichagoon P. A Multimicronutrient-fortified seasoning powder enhances the hemoglobin, zinc, and iodine status of primary school children in North East Thailand: a randomized controlled trial of efficacy. J Nutri. 2006; 136(3):1617-23.

3. Reddy MB, Hurrel RF, Cook JD. Meat consumption in a varied diet marginally influences nonheme iron absorption in normal individuals. J Nutr. 2006; 136(1):576-81 .

4. Pallarés IF. Effect of iron deficiency on the digestive utilization of iron, phosphorus, calcium and magnesium in rats. Br J Nutri. 1993; 70(1):609-20.

5. Agência Nacional de Vigilância Sanitária. Resolução da Diretoria Colegiada $n^{\circ}$ 63, de 6 de julho de 2000. Regulamento técnico para fixar os requisitos mínimos exigidos para a terapia de nutrição enteral. Diário Oficial da União. 2000, 6 jul.

6. Kreymann KG, Berger MM, Deutz NEP, Hiesmayr M, Jolliet P, Kazandjiev G. Espen Guidelines on enteral nutrition: intensive care. Clin Nutr. 2006; 25(2):210-23.

7. Azevedo, L. Desenvolvimento e avaliação de uma dieta enteral contendo proteínas hidrolisadas e fibras [mestrado]. Viçosa: Universidade Federal de Viçosa; 1996.

8. Vissotto FZ, Montenegro FM, Santos JM, Oliveira SJR. Avaliação da influência dos processos de lecitinação e de aglomeração nas propriedades físicas de achocolatado em pó. Ciênc Tecnol Aliment. 2006; 26(3):666-71.

9. Agência Nacional de Vigilância Sanitária. Resolução da Diretoria Colegiada $n^{\circ} 449$, de 9 de setembro de 1999. Regulamento Técnico referente a Alimentos para Nutrição Enteral. Diário Oficial da União. 1999, 13 set.

10. Peña LMR. Estudo da instantaneização de misturas contendo cacau em pó por aglomeração com jato de vapor [doutorado]. Campinas: Universidade Estadual de Campinas; 2003.

11. Maurel EC. Tecnologie des poudre. Granulation: tout un savoir-faire. Process: Le Mensuel des 
322 | L. AZEVEDO et al.

Techniques Laitieres et Alimentaires. 1994; 1095 : 62-65.

12. Association Official Analytical Chemistry. Official methods of analysis of the association of official analytical chemists. $14^{\text {th }}$ ed. Washington (DC): AOAC; 1990.

13. Hla PK, Hogekamp S. Wetting behaviour of instanized cocoa beverage powders. Food Sci Technol. 1999; 34(4):335-42.

14. Peleg M. Physical characteristics of food powders. In: Peleg M, Bagley EB, editors. Physical properties of foods. Westport (CT): AVI Publishing; 1983, p.293-321.

15. Barros SP, Manzano FM, Silva LBC. Manual de técnicas e receitas para espessamento de alimentos: utilização de diferentes amidos espessantes, Bauru: USP; 2008. p.19.

16. Norussis MJ. Statistical package for social science for Windows advanced statistics release 15.0. Chicago: SPSS; 2006.

17. Bueno L. Efeito do triglicerídeo de cadeia média, fibra e cálcio na disponibilidade de ferro, magnésio e zinco em uma formulação de alimentação enteral com otimização conjunta para os três minerais. Ciênc Tecnol Aliment. 2008; 28(Supl):125-34.

18. Cabre E. Fibre supplementation of enteral formuladiets: a look to the evidence. Clin Nutr Suppl. 2004; 1(2):63-71.

19. Gaiani C, Schuck P, Scher J, Desobry S, Banon S. Dairy powder rehydration: influence of protein state, incorporation mode, and agglomeration. J Dairy Sci. 2007; 90(2):570-81.

20. Barbosa-Cánovas GV, Ortega-Rivas E, Juliano P, Yan H. Bulk properties. In: Food power: physical properties, processing, and functionality. New York: Kluwer Academic; 2005. p.81-8.

21. Colugnati PG. Propriedades físicas e funcionais de aglomerados a base de proteína de soja [doutorado]. Campinas: Universidade Estadual de Campinas; 2003.

22. Silva LBC. Isolado protéico do soro de leite como perspectiva no cuidado nutricional de indivíduos com esclerose lateral amiotrófica [doutorado]. Campinas: Universidade Estadual de Campinas; 2008.

23. Daiuto ER, Cereda MP. Influência da granulometria de grânulos de amido sobre a densidade aparente de extratos atomizados. Rev de Ciênc Farm Bás Aplic. 2006; 27(1):51-6.

24. Vitali AA, Quast DG. Vida de prateleira de alimentos. In: Moura SCSR, Germen SPMM, editores. Reações de transformações e vida de prateleira de alimentos processados: manual técnico, n.6. Campinas: Ital; 1996. p.3-10.

25. Montejo O, Alba G, Cardona D, Estelrich J, Mangues MA. Relación entre la viscosidad de las dietas enterales y las complicaciones mecánicas en su administración según el diámetro de la sonda nasogástrica. Nutr Hosp. 2001; 16(2):41-5.

26. Ribas Al, Remacha JE, Giner J. Evolución del color, por efecto de la temperatura, en pulpas de fruta. Alimentaria: Rev Tecnol Hig Aliment. 1992; 234: 59-68.
Recebido em: 4/6/2009

Versão final reapresentada em: 12/11/2009 Aprovado em: 16/4/2010 